\title{
A REFORMA DO ENSINO
}

\author{
MARILENA DE SOUZA CHAUI
}

Refazendo a memória

Somos gente sem grande memória. Hoje os professores universitários e uma parcela dos professores do curso secundário lutam contra a Reforma do Ensino no Brasil e em especial contra a Lei 5692/71. Esta e suas sucessivas portarias regulamentam a implantação de Estudos Sociais e da licenciatura curta para formar professores polivalentes em ciências humanas no irrisório prazo de um ano e meio. Todavia, essa luta tende a aparecer sem amarras com qualquer passado e, conseqüentemente, sem qualquer vínculo com a própria história da reforma educacional. Já nos esquecemos de que a reforma foi posta em prática depois que o debate público e nacional em torno da Lei de Diretrizes e Bases foi sufocado para que a questão educacional se transformasse em mais uma, dentre as inúmeras, questão "técnica" a ser resolvida pelo aparelho estatal competente, isto é, pelo Conselho Federal de Educação. Este, como todo órgão centralizado e burocrático, passou a ditar cátedra sem dar ouvidos àqueles que poderiam discutir, avaliar e transformar aquilo que, para eles, mais do que uma profissão, é ofício e opção. Avivemos um pouco nossa memória.

A reforma do ensino no Brasil liga-se a um projeto educacional cujas linhas mais gerais foram traçadas pelo hoje esquecido projeto do acordo MEC-USAID. No presente, quando tantos universitários debatem acerca da soberania nacional e da autodeterminação política, já perderam de vista o fato de que, em suas origens, a proposta de reforma da educação não nasceu autodeterminada e soberana, mas veio sugerida do exterior. Grosso modo, nascido sob o signo da modernização, o projeto MECUSAID esteve assentado em três pilares: educação e desenvolvimento, educação e segurança, educação e comunidade.

$\mathrm{O}$ item educação e desenvolvimento propunha a formação rápida de profissionais que atendessem às necessidades mais urgentes do país no 
que respeita à tecnologia avançada. Incremento dos cursos de ciências aplicadas ou aplicáveis a curto e médio prazo, fundação de escolas especializadas em todo o país segundo as demandas regionais e financiamento de todos os empreendimentos particulares que pudessem ocupar-se do assunto em lugar do Estado, fizeram com que profissionalização rápida e privatização do ensino fossem, pois, colocadas como itens prioritários da reforma voltada para a criação de mão-de-obra especializada para um mercado em expansão. Nesse item, porém, permaneceu ignorada a natureza dos cursos considerados necessários. $\mathrm{Na}$ realidade, contudo, um leitor atento da proposta já podia ler o que estava escrito nas entrelinhas: a formação rápida dos profissionais na área de ciências e tecnologia não era problemática, visto que a idéia não era a de criar pesquisadores, mas executantes aptos de um saber vindo de fora e que não podia ser implantado no país sem grandes gastos se aqui não houvesse gente preparada para aplicá-lo. Educação e desenvolvimento, como não poderia deixar de ser, significava educação e reprodução da "dependência".

$\mathrm{O}$ item educação e segurança visava à formação do cidadão consciente. entendendo-se por consciência o civismo e o desejo de resolver os "problemas brasileiros". Outro prato da balança educacional, o tópico segurança já determinava de antemão a natureza do civismo e a dos problemas que seriam sugeridos aos educandos como sendo "brasileiros". Compensação humanística para o tópico tecnológico anterior, educação e segurança levaria à criação da disciplina Educação Moral e Cívica nos cursos médios e à de Problemas Brasileiros, nos cursos superiores. E visto que se tratava de educação moral, o projeto abria uma brecha para aquilo que se seguiu na prática, isto é, a extinção do ensino da Filosofia no curso secundário e seu desprestígio no curso universitário.

$\mathrm{O}$ item educação e comunidade é, sem dúvida, o mais expressivo. A relação da escola com a comunidade era proposta em termos genéricos: a comunidade diria à escola quais as questões mais urgentes ou prementes para a coletividade (local, regional, estadual etc.) e a escola responderia a tais carências formando pessoal capaz de atendê-las. Se a esse laço genérico e fraterno dava-se um fraco conteúdo, porém era-lhe dada uma forma muito forte, visto que a comunidade se faria ouvir pela escola através de representantes em conselhos que reunissem empresários e mestres. O tópico educação e comunidade traduzido em miúdos era o tópico referente à ligação escola-empresa e que iria traduzir-se em Conselhos Universitários compostos de professores e representantes dos vários setores do patronato (indústria, comércio e agricultura).

A proposta MEC-USAID rezava e preconizava a "integração das escolas à realidade social", entendendo por tal integração o fornecimento de mão-de-obra às empresas e o surgimento de uma elite de pesquisadores (que, como já observei, seria uma elite de tudo, menos de pesquisa). Na prática, essa proposta desembocou nos cursos profissiona- 
lizantes do Ensino Médio e nos cursos de Pós-Graduação do Ensino Superior. A escola aparece diretamente vinculada à empresa tanto no que tange à predeterminação da natureza da mão-de-obra considerada necessária, quanto no que tange ao barateamento dessa mão-de-obra, na medida em que a escola satura o setor da oferta face ao da demanda. $\mathrm{O}$ vínculo produz uma tríplice desqualificação profissional: em primeiro lugar, porque o profissional aqui produzido é inferior ao profissional produzido em outros países; em segundo lugar, porque cria um verdadeiro exército de reserva de profissionais que aceitarão qualquer serviço por qualquer salário; em terceiro lugar, porque além de aviltar o profissional, cava um fosso entre ele e os considerados como não qualificados. Se a presença da comunidade se faz sentir dentro da escola, isto se dá de maneira discricionária, uma vez que a comunidade é identificada com os empresários que participam dos conselhos e decidem quanto aos curriculi, vagas, contratação de professores, bolsas de estudo etc. Todavia, a presença da empresa se faz sentir ainda de uma outra maneira: as eszolas serão estruturadas segundo o princípio da organização, isto é, terão forma idêntica ou muito semelhante-à das empresas; serão, portanto, fortemente burocratizadas e hierarquizadas. Por esta razão, o princípio, da autonomia universitária pode ser defendido igualmente por gregos e troianos visto que, tendo conselhos mistos que decidem o destino da escola, a autonomia não se refere a uma escola autônoma, e sim a uma empresa autônoma. O projeto MEC-USAID, aliás, propõe que se substitua a expressão "autonomia universitária" por "autogerência flexível". Que significa essa pequena alteração lingüística? Significa simplesmente que é proposto que as escolas se auto-sustentem gerando lucros, o que farão desde que sejam escolas pagas. Assim, conforme à reforma projetada a "comunidade" deverá pagar pelo lucro que irá auferir mais tarde. Na mesma linha de argumentação que propõe a necessidade do ensino público pago, o projeto previa a necessidade de criar condições para a proliferação das escolas privadas, propostas pela "comunidade" segundo suas necessidades "próprias". Em suma, o tópico escola-comunidade propunha a gradativa transformação da escola em empresa encarregada de reproduzir com sucesso o capital.

Duas coisas são fundamentais no projeto MEC-USAID: por um lado, a transformação da estrutura da escola rumo ao modelo organizacional das empresas, o que facilita sobremaneira o controle institucional do ensino; por outro lado, a exigência de que a reforma fosse feita de modo gradual e paulatino, sem grandes contradiçð̃es com a antiga estrutura vigente, de sorte que ao final de um certo prazo estivesse implantada sem alarido. Pode-se dizer que do ponto de vista legal ou formal o projeto foi cumprido sem falhas. O mesmo, porém, não pode ser dito do ponto de vista material, isto é, quanto ao conteúdo e aos gastos sociais de sua implantação. Dificuldades e contradições não se fizeram esperar e o caso de Estudos Sociais e da licenciatura curta é exemplar. 
Dois aspectos bastam para deixar patente a distância que separa a intenção "inovadora" da reforma e a realidade de sua prática. Trata-se, de um lado, dos motivos alegados em seu favor e, de outro lado, do tipo de conhecimento que através dela é veiculado.

Alegando que para reformar o ensino era necessário considerar preferencialmente aquelas regiōes do pais mais desfavorecidas do ponto de vista sócio-econômico, os reformadores afirmaram que o padrão e os critérios do ensino nas regiōes mais privilegiadas não poderiam servir de parâmetro para a reforma. Era de se imaginar, em primeiro lugar, que a reforma tivesse dado ênfase a critérios regionais, mas não foi o caso, visto que a lei é nacional. Os únicos aspectos supostamente locais ou regionais a serem respeitados estariam vinculados aos cursos profissionalizantes, segundo o projeto escola-comunidade do MEC-USAID. Ora, as aberrações não se fizeram esperar. A falta de recursos materiais e humanos, de um lado, e a busca do lucro, de outro lado, fazem com que os cursos profissionalizantes sejam tudo quanto se queira, menos profissionalizantes. Não é raro, pelo contrário, é a regra, cursos para formar office-boys, ministrados por dentistas ou advogados locais em regiões onde a oferta de trabalho se concentra em tarefas agrícolas ou em pequenas indústrias do tipo olaria. Não é raro e sim costumeiro que cursos destinados a profissionalizar alunos em eletrônica sejam ministrados pelo rádio-amador local e que, não dispondo dos instrumentos para ministrar as aulas, limita-se a mostrar gravuras aos alunos e a dar-lhes informações abstratas acerca do trabalho que um dia irão realizar. Não menos aberrante é o fato de que as escolas que efetivamente deveriam profissionalizar os alunos do ensino médio, isto é, as escolas públicas em geral e as das periferias dos grandes centros urbanos, sejam exatamente aquelas que não dispõem de recursos materiais para fazê-lo, enquanto, ao contrário, as escolas particulares, cuja clientela irá profissionalizar-se na universidade, sejam aquelas que dispõem de condições para uma profissionalização inútil. Porém, não é nesse ponto que melhor podemos perceber o sentido da reforma. Se para realizá-la, especialmente no que tange ao curso médio, havia falta de professores, a implantação de Estudos Sociais no secundário exigia a formação rápida de docentes. Com este argumento, a licenciatura curta ofereceu-se como panacéia. Ora, era de se esperar que essa modalidade de formação de professores fosse provisória e, sobretudo, que fosse feita justamente naquelas regiões desfavorecidas que contavam com pequeno número de docentes. $O$ que não é o caso. Não só a licenciatura curta tende a se tornar definitiva e a ocupar o lugar da licenciatura longa, como ainda os locais onde a implantação dos professores curtos em Estudos Sociais alcançou maior êxito numérico e financeiro foram exatamente aqueles nos quais a reforma não parecia exigir tais medidas, isto é, nos grandes centros urbanos do Centro-Sul, em especial $\mathrm{S}$. Paulo. Teria sido isto um pequeno engano do laissez-faire, ou estaria na lógica da coisa que a reforma fosse implantada com sucesso ali onde 
seria fonte segura e rápida de lucro? Com efeito, alegando que o Éstado sozinho não poderia arcar com as despesas da reforma, incentivou-se, em consonância com o espírito do acordo MEC-USAID, a proliferação das empresas privadas da cultura, para as quais a licenciatura curta em Estudos Sociais é um presente divino. Com ela saem lucrando tanto facul. dades quanto colégios particulares. Não só as primeiras, podem, no prazo irrisório de um ano e meio, formar, professores, como as segundas podem empregar um único professor polivalente para ministrar toda a área dos Estudos Sociais. As primeiras podem encurtar rapidamente uma fornada de jovens estudantes, despachá-los com pitadas de conhecimentos dadas por cozinheiros duvidosos e logo voltar a encher as salas com novas turmas a serem encurtadas.

$\mathrm{O}$ que é um professor curto? Qual o interesse em produzi-lo? Um professor encurtado é curto sob todos os aspectos: formado em tempo curto, a curto preço para a escola, (mas a alto custo para o estudante), intelectualmente curto. Em suma, um profissional habilitado a dar aulas medíocres a preço módico, pois é remunerado exclusivamente em termos de hora-aula, sem que entre no cômputo o tempo gasto em preparar cursos e corrigir trabalhos, como não entram no cômputo os gastos de locomoção, com materiais de que necessita para ministrar a aula (livros, sobretudo) etc. Esse professor, incapacitado para a pesquisa, seja porque não recebeu formação suficiente para tanto, seja porque não dispõe de condições materiais para tentar cursos de pós-graduação onde pudesse pesquisar, é um professor que interessa muito, pois é dócil. Dócil às empresas porque é mão-de-obra farta e barata, quase desqualificada; dócil ao Estado, pois sua formação precária e estreita e as péssimas condições de sobrevivência não the permitem chegar a uma atitude reflexiva face à sociedade e ao conhecimento. A reforma traz, assim a desqualificação integral do professor, seja em termos sociais, seja em termos intelectuais. Com essa desqualificação, que é uma degradação, rebaixa-se ainda mais o nível dos cursos secundários e superiores, e prepara-se a morte da pesquisa.

O outro aspecto da reforma que merece atenção concerne à idéia do saber. A lei introduz para o ensino do primeiro e segundo graus os termos: atividades, áreas e disciplinas. As atividades estão referidas às experiências vividas pelos alunos, de sorte que a tarefa inicial da escola é a de fazer chegar à consciência da criança aquilo que é vivido espontaneamente por ela. Visto que tais experiências tendem a ser fragmentárias e dispersas, a tarefa das áreas e posteriormente a das disciplinas é definida como organização e sistematização daquelas experiências na forma de conhecimentos. Aparentemente, a reforma é progressiva, introduz a école buissonnière na escola instituída, "motiva" a criança, alarga seus horizontes. Basta, porém, um pouco de reflexão para que essa aparência se dissolva. Com efeito, longe de o conhecimento ser tomado como reflexão e como crítica dos dados da experiência, a lei afirma que o conhecimento é a organização e a sistematização da experiência imediata. 
Há, pois, na base da lei, um empirismo grosseiro que supõe ser o conhecimento a mera continuação equilibrada e ordenada daquilo que a experiência imediata fornece dispersamente. Nessa medida, quando criticamos a reforma dizendo que é a morte da pesquisa, cometemos um engano, afinal. Para considerarmos que os reformadores visavam, através do professor curto e de Estudos Sociais, a exterminar a pesquisa, seria preciso que admitíssemos que sabem o que é pesquisa. Ora, a lei deixa claro como a luz do meio-dia que os reformadores não têm a menor idéia do que seja a pesquisa, uma vez que desconhecem a produção do conhecimento, pois o reduzem à sistematização e ordenação dos dados imediatos; jamais visam a ele como compreensão do sentido da experiência. Sob esse aspecto, a reforma é ainda mais lamentável do que poderiamos supor, na medida em que os reformadores sequer podem compreender a crítica que lhes é endereçada: simplesmente não sabem do que estamos falando.

Também não podemos negligenciar as implicaçð̃es da hierarquização do conhecimento em atividades, áreas e disciplinas. Não só a hierarquia supõe a passagem contínua e homogênea da experiência ao saber, como supõe que entre ambos a diferença não é de natureza mas apenas do grau de complexidade, e ainda alimenta a confusão entre uma concepção interdisciplinar do conhecimento e uma concepção polivalente ou integradà. Se esta confusão tem resultados muito vantajosos no plano prático, como por exemplo permitir às escolas privadas empregar um único professor polivalente ou integrado em lugar de vários professores, todavia, tem implicações teóricas graves, porquanto são concernentes ao estatuto ideológico dado ao conhecimento. Com efeito, a integração das diferentes esferas do conhecimento pressupõe uma uniformidade de pontos de vista que diferem apenas pelo tipo de objeto que conhecem, mas que são partes harmônicas e harmoniosas do mesmo todo que seria o saber. A integração exclui, por definição, a contradição, os antagonismos, as tensões entre os vários domínios do conhecimento. $\mathrm{E}$ visto que a reforma supõe uma continuidade entre a experiência e o conhecimento, pressupõe que o real, enquanto dado pela experiência, também é integrável e hamonioso, de sorte que a unificação proposta para os conhecimentos é pressuposta como devendo realizar-se no mundo. $\mathrm{O}$ conhecimento, espelho ordenado de uma realidade que a experiência forneceria desordenadamente, está encarregado de fazer chegar à nossa consciência a idéia de um mundo unitário e sem tensões. A tensão máxima que se poderia admitir seria aquela entre o "velho" e o "novo", tensão que a idéia de progresso tende a anular. Jamais se dirá que as contradições entre as esferas do conhecimento exprimem de maneira determinada as contradições efetivas da sociedade. Entre a experiência e o conhecimento a diferença é de grau, como é de grau a diferença entre a realidade e o saber. Sob a camada do empirismo grosseiro e de uma visão grotesca do saber e do social esconde-se algo que é intrínseco a uma concepção 
burocrática da razão e da sociedade. A pax rationalis e a pax socialis sustentam uma reforma do ensino que nada mais é do que uma das expressões da reforma do exercício do poder burocrático. Emanando do alto e do exterior, a reforma elabora uma imagem do conhecimento destinada a ocultar a distância que separa a experiência e o conhecimento, a escamotear os conflitos entre as várias esferas do saber e a mistificar o movimento reflexivo e crítico do conhecimento em nome de uma racionalidade imaginada como integração e ordenação. Essa ideologia, que aqui se exprime no plano pedagógico, visa a inculcar nos estudantes a imagem de que são membros de uma sociedade homogênea e harmoniosa, na qual as diferenças entre os cidadãos decorrem de diferenças naturais ou nascidas do acaso e na qual os conflitos são um mero acidente de direito suprimivel. Saber integrado e sociedade integrada são uma só e mesma coisa.

\section{A situação da Filosofia}

Proponho, desde logo, aproveitando a oportunidade deste Encontro, uma declaração, firme e decidida a favor da manutenção do ensino da $\mathrm{Fi}$ losofia no curriculo do ensino secundário, hoje ameaçado por uma nova reforma que, parece, pretende eliminá-lo.

Cruz Costa, 1958

Os professores de Filosofia que recebem os estudantes para o primeiro ano dos cursos universitários não se cansam de constatar o que já se tornou um lugar-comum: o baixo nível dos alunos. Evidentemente, há a tendência a responsabilizar as deficiências do curso médio pela má formação dos estudantes, seja em decorrência do estilo da aprendizagem (o famoso "estudo dirigido" e as malditas "cruzinhas"), seja como conseqüência da pobreza e imprecisão do conteúdo das informações que recebem, seja pelo desconhecimento da língua portuguesa e das línguas estrangeiras, seja, enfim, pela ausência de uma visão mais abrangente da natureza do trabalho teórico, ausência que decorre de uma outra, isto é, do vazio deixado pela supressão do ensino da Filosofia no curso secundário.

Passado o primeiro momento de desânımo face aos novos alunos os professores são levados a indagar o que se passa no ciclo médio. Certamente muita coisa se passa ali após a implantação de Educação Moral e Cívica, de Estudos Sociais ministrados por licenciados curtos e após a introdução dos célebres guias curriculares que uniformizam o precário conteúdo dos cursos ministrados. Embora de modo geral os professores 
universitários ignorem o que se passa com seus colegas do secundário, todavia não thes escapa o que se passa com os alunos, não sendo difícil imaginar as imposições a que os colegas se encontram submetidos para enviar às universidades os alunos que enviam.

Os alunos de Filosofia têm queixas a fazer. Queixam-se da dificuldade para compreender o que lhes é transmitido e da dificuldade para acompanhar os cursos com a bibliografia que lhe é indicada, mesmo quando os textos são em língua portuguesa. Quem se deu ao trabalho de examinar os livros usados pelos estudantes durante o curso secundário não se espantará ao vê-los perdidos diante da bibliografia nova e do discurso do novo professor. Os textos usados no secundário primam pela confusão entre o empírico e o concreto, confusão que transparece nos recursos audiovisuais para explicar a teoria dos átomos ou o sistema circulatório - no primeiro caso o átomo é definido como "uma bolinha que não se divide" e é ilustrado por molequinhos a brincar de roda; no segundo caso, ilustra-se o sistema circulatório pelo sistema viário, pedágio incluso, de tal modo que a coisificação do corpo humano e a antropomorfização do sistema viário os torna indiscerníveis. Textos de História explicam de maneira convincente que não há progresso (o que é verdade) porque tudo é relativo e o historicismo passa a ocupar o lugar de honra na reflexão dos estudantes, pois lhes dá uma resposta apaziguadora para a inquietante questão acerca do sentido da sociedade e da história. Os compêndios de Comunicação e Expressão, examinados por Osman Lins em Do Ideal e da Glória - Problemas Inculturais Brasileiros, são estarrecedores. Verdadeira disneilândia que toma como ponto de partida a suposição de que os alunos são imbecis, os compêndios são oferecidos à leitura com anúncios de que "literatura é gostoso" e raramente essa "coisa gostosa" vai além de "Meus Oito Anos", "A Agulha e a Linha", "As Pombas", trechos da Inocência ou Iracema, entremeados de outros da lavra do compilador. Seria inútil nos alongarmos em exemplos. O que interessa é perceber o que ocorre com os alunos quando, habituados a pensar desta maneira, enfrentam os textos do Platão, Aristóteles, Descartes, Kant ou Hegel.

Todavia, os estudantes têm ainda outra queixa e se a compreendermos teremos avançado na questão. Queixam-se de não acompanhar o que o professor lhes diz, de não perceber o que tal discurso tem a ver com o mundo dado de suas experiências e como poderão escrever acerca daquilo que não conseguiram sequer ouvir. Essa queixa nos conduz ao efeito, quiçá o mais drástico, do curso secundário pós-reforma. Sistematicamente cortados de uma relação significativa com a linguagem e com todas as vias expressivas, os jovens estudantes não sabem ouvir, ler e escrever. Durante o secundário, a linguagem foi reduzida à dimensão meramente denotativa ou indicativa, de sorte que a relação entre as palavras e as coisas nunca passsasse pela mediação das significações. Reduzida ao esquema binário da relação signo-coisa, a linguagem foi 
exilada da esfera do sentido e da região que lhe é própria, isto é, da expressão. Não nos deve, pois, espantar que os estudantes, recém-saidos de um curso dito "integrado" sejam incapazes de perceber e de formular as relações mais simples, de apreender as articulações mais elementares entre o que ouvem ou lêem e o mundo onde vivem. Impedidos de um acesso verdadeiro à linguagem, estão impedidos de um acesso verdadeiro ao pensamento e, conseqüentemente, da possibilidade de alcançarem o real, sempre confundido com os dados imediatos da experiência. Ora, qual é o instrumento de trabalho da Filosofia? De onde partem as reflexões e as críticas? Da linguagem. Esfera privilegiadamente discursiva do saber, a Filosofia se realiza através da compreensão da origem das significações constituídas pela linguagem e, assim sendo, compreende-se que a lamentação do estudante de Filosofia é mais do que lamúria ou incompetência: é a queixa daquele a quem foi roubado o direito à palavra.

No curso secundário, a Filosofia foi deixada à margem. Os curriculi foram organizados tendo matérias obrigatórias que constituem o chamdo núcleo comum e do qual a Filosofia foi excluída, sendo relegada à condição de matéria optativa. A opção, todavia, não era feita pelos alunos, mas pelo diretores das escolas que decidiam manter ou não um curso de Filosofia. Dos duzentos e cinqüenta colégios estaduais de São Paulo, apenas dezessete conservaram Filosofia na qualidade de optativa; nos demais colégios, desapareceu. Essa situação precária terminará definitivamente a partir de 1978 quando as grades curriculares feitas pela Secretaria da Educaça to Estado de São Paulo determinarem o curriculum do secundário; a Filosofia foi inteiramente extinta. $\mathrm{O}$ argumento apresentado para a extinção é duplo: por um lado, a carga horária exigida para os cursos profissionalizantes é muito grande para que as escolas ainda comportem o peso de disciplinas optativas não profissionalizantes; por outro lado, não se pode fazer com a Filosofia o que se pode fazer com outras matérias, isto é, colocá-las no profissionalizante a título de aplicação prática dos conteúdos desenvolvidos teoricamente pelas mesmas matérias no núcleo comum. Assim, por não profissionalizar e por não ser "aplicável", a Filosofia perdeu qualquer lugar no ciclo médio. Resta ver se o imediatismo da reforma e os argumentos alegados para a exclusão da Filosofia são os únicos ou os verdadeiros motivos que devemos aceitar.

Cumpre lembrar, antes de tudo, que a supressão é facilitada pelo fato de ter sido precedida pela passagem da Filosofia à condição de optativa, de sorte que sua quase inexistência anterior preparou gradativamente um consenso difuso acerca de sua abolição necessária. Por outro lado, a supressão também é facilitada pelo fato de que os professores de Filosofia, no decorrer dos últimos anos, foram sendo paulatinamente transferidos para outras matérias, como Educação Moral e Cívica e História, de maneira que, tendo aceitado um remanejamento que lhes permitia sobreviver como professores, já não se surpreendem com a extinção final 
que só os afeta longinquamente, isto é, enquanto professores que desejariam lecionar a matéria para a qual se prepararam nas universidades. A transferência para outras disciplinas ou áreas tem três efeitos sobre os professores: o primeiro, consiste em incentivá-los para uma licenciatura curta em Estudos Sociais em faculdades privadas onde nem mesmo sejam obrigados a assistir às aulas (reforçam, assim, reforma no plano universitário e secundário); o segundo consiste em desmobilizá-los para qualquer atitude de luta pelo retorno da Filosofia, visto que tal retorno implicaria uma crítica global da reforma, coisa que não se sentem preparados e fortalecidos para realizar; em terceiro lugar, alimenta a imagem da versatilidade do professor de Filosofia que pode falar sobre qualquer coisa que lhe peçam, pois a Filosofia é, para o senso-comum, a capacidade para falar sem nada dizer. Assim, os professores do curso secundário são engolidos pela reforma e servem de pasto para ela. Esta situação foi confirmada por levantamentos feitos por alunos e professores do Departamento de Filosofia da Universidade de São Paulo que, entrevistando os poucos professores que ainda lecionam Filosofia notaram a presença de três atitudes diferentes, mas convergentes: há os professores que não estabelecem a menor relação entre a implantação de Moral e Cívica e Estudos Sociais e a supressão da Filosofia, pois o processo foi tão gradual que o vínculo permaneceu escondido; há os professores que percebem perfeitamente essa relação, mas que se sentem desanimados para tentar qualquer luta em sentido contrário, pois as decisões referentes ao ensino são de tal modo transcendentes aos professores que estes nem sabem por onde passaria um combate eficaz; há, enfim, os professores que tem consciência da reforma como um todo e que desejam encontrar vias para combatê-la, mas que se defrontam com uma dispersão tão grande entre seus colegas que não sabem como seria possivel sensibilizálos para uma atitude mais crítica e combativa. Essas atitudes revelam a eficácia do sistema burocrático que fragmenta as decisões, ao mesmo tempo em que as faz depender de uma instância superior e externa, de sorte que pela fragmentação impede a visão globalizada do processo e pela transcendência impele à submissão a algo tido como inevitável.

Um outro levantamento de dados mostrou que os professores das demais matérias do núcleo comum se ressentem da supressão da Filosofia. Segundo eles, a extinção teve efeitos sobre seus próprios cursos ao perderem a contribuição do professor de Filosofia que ministrava aos alunos cursos nos quais os fundamentos teóricos e históricos do que era aprendido nas outras disciplinas era criticamente examinado. Ora, como os demais professores não se sentem capacitados a oferecer tais conhecimentos, notaram como um primeiro efeito da desaparição da Filosofia o surgimento de perguntas a que não podiam responder e o desinteresse dos alunos pelo que aprendem, pois afora o interesse imediato suscitado pelos exames vestibulares, não alcançam o sentido mais amplo daquilo que lhes é ensinado. A melhor prova dessa situação e do desamparo em 
que e encontram os outros professores, nos foi dada durante um curso de extensão universitária acerca do ensino da Filosofia no secundário. O curso foi organizado por uma comissão de professores do Departamento de Filosofia da USP voltada para a luta do retorno da Filosofia ao ciclo médio. Para surpresa dos organizadores, a maior parte dos inscritos eram professores de outras matérias, especialmente as do núcleo comum de Estudos Sociais. Indagados sobre qual interesse tal curso possuía para eles responderam invariavelmente da mesma maneira: estavam tentando adquirir subsídios filosóficos para seu trabalho pedagógico, uma vez que já não contavam com o apoio do professor de Filosofia para isso.

Um outro levantamento realizado por essa comissão trouxe um dado paradoxal: a supressão da Filosofia no curso secundário acarretou sua presença maciça nos ciclos básicos das faculdades que aderiam à reforma. Indagados a esse respeito, diretores e professores invariavelmente responderam afirmando que a Filosofia, mesmo a título introdutório, é indispensável para a compreensão dosproblemas teóricos que os estudantes enfrentarão no decorrer dos cursos especializados. $\mathrm{O}$ argumento, aqui, é muito semelhante ao dos professores secundários, isto é, assentase na idéia de que a Filosofia sendo uma reflexão acerca dos fundamentos do conhecimento e da prática é indispensável para todo e qualquer trabalho intelectual.

Dois outros dados, não menos paradoxais ou sintomáticos merecem atenção. O primeiro se refere ao aumento do número de alunos que escolhem em primeira opção o curso de Filosofia, na USP, quando há algum tempo atrás predominavam alunos de quinta e sexta opção. O segundo, concerne ao aumento da solicitação de cursos de Filosofia por parte de outros departamentos e institutos da USP, mas não só da USP e sim de outras universidades no Estado de São Paulo e de outros estados. E cursos não somente para alunos de graduação e pesquisadores, como também cursos para professores universitários e pesquisadores. Estas solicitações, em nosso caso, são atendidas com grande dificuldade, pois as verbas para a contratação de professores de Filosofia na universidade são parcas, irrisórias, e em geral, inexistentes.

Um questionário distribuído aos alunos inscritos em Filosofia no primeiro ano em 1977 revelou que a maioria dos estudantes que escolheu Filosofia em primeira opção segue ou já completou outros cursos universitários. Evidentemente, saita aos olhos que só é possível escolher Filosofia depois de assegurar a sobrevivência de outra maneira. Contudo, respondendo ao questionário, os estudantes justificavam a escolha pela mesma razão que tem levado outras unidades da universidade (paulista ou não) a solicitar cursos de Filosofia: o desejo de uma compreensão crítica das atividades que realizavam.

$\mathrm{O}$ que fica claro nesse quadro é que a Filosofia não é buscada como contraponto ou contrapeso humanístico para a vertigem tecnológica e tecnocrática que assola o país (e o mundo...) mas porque se espera dela 
algo que o imediatismo não pode alcançar. Os cientistas que procuram a Filosofia começam com questões metodológicas, desejosos de não prosseguir seus trabalhos às cegas. Pouco a pouco, todavia, as questões metodológicas vão deixando transparecer um outro solo de questões mais amplas acerca do trabalho teórico e de suas articulações com a realidade histórica. Chegados a este ponto, os pesquisadores novamente solicitam a contribuição da Filosofia e salta aos olhos a verdadeira razão para extingui-la do secundário e para minimizá-la na universidade através da política das verbas e da implantação de Estudos Sociais e licenciatura curta. $\mathrm{O}$ que se costuma solicitar à Filosofia é que ilumine o sentido teórico e prático daquilo que pensamos e fazemos, que nos leve a compreender a origem de idéias e valores que respeitamos ou que odiamos, que nos esclareça quanto à origem da obediência a certas imposições e quanto ao desejo de transgredi-las, enfim, que nos diga alguma coisa acerca de nós mesmos, que nos ajude a compreender como, por que, para quem, por quem, contra quem ou contra o que as idéias e os valores foram elaborados e o que fazer deles.

Evidentemente, pede-se muito à Filosofia e ela, que em geral tem mais questões a colocar do que respostas a dar, não pode permanecer em silêncio, sobretudo em uma sociedade na qual questionar tornou-se um crime. Se a Filosofia se oferece como crítica da cultura, certamente não pode ser vista como uma preciosa auxiliar para a reprodução de sistemas de dominação e, assim, sob alegações de ordem "técnica" procura-se suprimi-la. Se a filosofia desmistifica a proposta de uma sociedade burocratizada modelada à imagem do pricípio da organização, tida como cânone da racionalidade no mundo contemporâneo, se desmistifica o ideal modernizador de uma sociedade tecnológica, se desmitifica propostas autoritárias que pretendem impor-se pela via pedagógica (como é o caso da atual reforma do ensino, vinda do alto), se desmistifica o progressismo pedagógico e o conformismo na arte e na política, torna-se clara a razão de sua supressão e a natureza das disciplinas encarregadas de substitui-las. Mas, talvez, compreendamos também porque sua supressão não interessa àqueles que se sentem concernidos por uma tarefa que reconhecem como histórica. Num mundo destinado ao silêncio, a Filosofia, que é discurso, talvez deva ser defendida e talvez valha a pena lutar pela liberdade de interrogar. 